"Does the inverse exchange-traded fund trading convey a bearish signal to the market?"

\begin{tabular}{|c|c|c|}
\hline AUTHORS & Jung-Chu Lin & \\
\hline ARTICLE INFO & $\begin{array}{l}\text { Jung-Chu Lin (2016). Does the i } \\
\text { bearish signal to the market?. In } \\
\text { Innovations, } 13(2-2), 279-284 . \mathrm{d}\end{array}$ & $\begin{array}{l}\text { raded fund trading convey a } \\
\text { nent and Financial } \\
(2-2) .2016 .02\end{array}$ \\
\hline DOI & http://dx.doi.org/10.21511/imfi.13 & \\
\hline RELEASED ON & Thursday, 14 July 2016 & \\
\hline JOURNAL & "Investment Management and F & \\
\hline FOUNDER & LLC “Consulting Publishing Cor & erspectives" \\
\hline & & $\begin{array}{l}= \pm \\
= \pm=\end{array}$ \\
\hline NUMBER OF REFERENCES & NUMBER OF FIGURES & NUMBER OF TABLES \\
\hline
\end{tabular}

(C) The author(s) 2022. This publication is an open access article. 
Jung-Chu Lin (Taiwan)

\title{
Does the inverse exchange-traded fund trading convey a bearish signal to the market?
}

\begin{abstract}
This paper investigates whether inverse exchange-traded fund (ETF) trading can predict future negative underlying index returns. Using inverse ETF's turnover rates and price volatilities to represent trading activities, this paper discovers that inverse ETF trading is significantly and positively related to future index returns and infers that the trading of inverse ETFs may not reflect informed pessimistic trading and cannot convey a bearish signal to the market. The trading activities in inverse ETFs do provide information about future index returns, yet what they reflect may be a lagging or less-informed bearish signal.
\end{abstract}

Keywords: inverse exchange-traded fund, bearish signal, informed pessimistic trader, underlying index return. JEL Classification: G12, G14, G18.

\section{Introduction}

While exchange-traded funds (ETFs) make spot index trading feasible, the advent of inverse ETFs completes the layout of the trading. As shorting in spot market is generally constrained by stricter regulation and requirements, short sellers cannot respond to information they possess as timely and conveniently as optimistic investors, hence, they underreact to the information. Prior studies do demonstrate that short-sale constraints may impede stocks' rapid impounding value-relevant information, especially the bad news, and lead to an overvaluation of stocks and an asymmetric price discovery process (Boehme et al., 2006; Bris et al., 2007; Chang et al., 2007; Diamond and Verrecchia, 1987; Miller, 1977). The trading of inverse ETFs, therefore, is a possible way to mitigate market-wide short-sale constraints and allows short sellers, whom are generally considered those who can predict future negative stock return better, to sell short in the spot market and to return the inverse of the index price movements. Accordingly, this article aims to investigate whether the trading of inverse ETFs stands for informed pessimistic trading and can convey a bearish signal to the rest of the market about the underlying index's future prospects.

Prior literature considers short-selling activity as a bearish signal to the market. Senchack and Starks (1993) show that unexpected increases in short interest precipitate negative, albeit small, returns around short-interest announcements. Aitken et al. (1998) examine the Australian stock market and find that large short sales precede negative abnormal returns. Other studies also report the negative and significant abnormal returns on stocks with high short interest and further document a negative correlation between market returns and short interest

(C) Jung-Chu Lin, 2016

Jung-Chu Lin, Associate Professor, Department of Banking and Finance, Takming University of Science and Technology, Taiwan.
(Ackert and Athanassakos, 2005; Angel et al., 2003; Asquith et al., 2005; Dechow et al., 2001; Desai et al., 2002; Farinella et al., 2001). In recent studies, Boehmer et al. (2010) find that stocks with the lowest short interest have positive monthly alphas greater than $1 \%$ and outperform stocks with the highest short interest by more than 2\%; Zhou and Wong (2011), using data of the Chinese stock market, find that short-sold stocks have poorer performance than stocks that are not subject to short selling.

Miller (1977) shows that bullish investors can push stock prices to a level that overvalues the stocks, if short selling is constrained. Theoretically, short sellers, whom are considered informed traders, would short these overvalued stocks, thereby producing a phenomenon: stocks with high short interest ratios have subsequent negative returns (Diamond and Verrecchia, 1987). On empirical evidence, stocks with short-sale constraints do exhibit lower returns in the subsequent month (Bris et al., 2007; Jones and Lamont, 2002). Short sellers are contrarian in contemporaneous and past returns and able to predict price reversals impressively (Diether et al., 2009). However, in some studies (Brent et al., 1990; Figlewski, 1981; Figlewski and Webb, 1993; Woolridge and Dickinson, 1994; Blau and Brough, 2011; Sum and Lin, 2015), the results do not support the above argument that short-selling activities can predict price reversals well. Blau and Brough (2011) even conclude that inverse ETF trading does not provide any information about future returns nor does this trading reflect a reliable bearish signal to the market.

This paper mainly refers to the methods in Diether et al. (2009) and Blau and Brough (2011) and examines if the trading of inverse ETFs predicts future negative index returns and reflects informed pessimistic traders' opinion. The main finding is contrary to the idea that inverse ETF trading provides a bearish signal to the market; that is, the 
results show that the trading of inverse ETFs does not predict future negative index returns and cannot stand for informed pessimistic trading. The trading activities in inverse ETFs do provide information about future index returns, yet what they reflect may be a lagging or less-informed bearish signal. Inverse ETF's trading is more like a panic index. Therefore, the findings suggest that investors, at least, should not interpret abnormally high turnover in inverse ETFs as a bearish signal.

\section{Model and methodology}

This paper modifies the general framework in Diether et al. (2009) and Blau and Brough (2011) and constructs a testing model as equation (1) to explore whether short sales through inverse ETFs can predict subsequent index returns,.

$X_{-}$ret $_{i,(t+1) o,(t+j) c}=\alpha+\beta_{1}$ turn $_{i, t}+\beta_{2}$ Pvolt $_{i, t}+\beta_{3}$

$X \_r e t_{i(t-j+1) o, t c}+\varepsilon_{i, t}$,

The dependent variable is the subsequent underlying index return for ETF $i$ from day $(t+1)$ open to $(t+j)$ close, $j=1,2, \ldots, 5$. As independent variables, this paper includes the current ETF turnover, turn $_{i, t}$ (share turnover or turnover rate), the current ETF price volatility, $P$ volt $_{i, t}$ (high-low price volatility or open-high-low-close price volatility), and the lagged index return, ret $_{i(t-j+1) o, t c}$. turn $_{i, t}$ is the share turnover or turnover rate in the trading day $t$ for ETF $i$; Pvolt $_{i, t}$ is the ETF price volatility over the trading day $t$ for ETF $i$; ret $\operatorname{rit}_{i(-j+1) o, t c}$ is the underlying index return for ETF $i$ from day $(t-j+1)$ open to day $t$ close, $j=1,2, \ldots, 5$. As Blau and Brough (2011) have indicated, if trading activities in inverse ETFs represent a bearish signal, the turnover and future index returns should be negatively related. Since the sample includes three ETFs (cross sections) over October 31, 2014 to December 31, 2015 (time series), this paper applies panel estimation method to estimate equation (1).

\section{Data and summary statistics}

Nine inverse ETFs have been listed on the Taiwan Stock Exchange ever since their first launch, Yuanta Daily Taiwan 50 Bear -1X ETF, on October 31, 2014. The underlying indices these inverse ETFs inversely track spread over six different markets, including Taiwan, China, Japan, United States, Hong Kong and India. Considering the need for sufficient data length, this paper chooses the first three inverse ETFs to form the sample.

The three inverse ETFs included are Yuanta Daily Taiwan 50 Bear -1X ETF (code: 00632R), Fubon SSE 180 Inversed Index ETF (00634R) and Yuanta Daily CSI 300 Bear -1X ETF (00638R), each of which tracks the inverse performance of Taiwan 50 index, Shanghai Stock Exchange (SSE) 180 Index and CSI 300 daily return index ${ }^{1}$, respectively. Daily share turnover, share turnover rate and two volatility measures of the three inverse ETFs are used to represent the trading activities, while five future index returns with different trading periods (from one day to five days) are calculated to represent future index returns. Lagged index returns with identical trading periods with the future index returns are also computed and included in the model to explain the future index returns. Share turnover and turnover rate data can be obtained directly from the Taiwan Economic Journal (TEJ) database where the daily share turnover rate is defined as the $\%$ age of shares outstanding that are traded on a particular day. The volatility measures, future and lagged index returns are computed from daily trading price data, which are also gathered from TEJ database. One volatility measure, $H L_{-}$volt , is the difference between the daily high price and the daily low price scaled by the daily high price (Diether et al., 2009), and the other measure, OHLC_volt, is calculated as follows (Garman and Klass, 1980):

$$
\text { OHLC_volt } \text { tit }=\sqrt{\frac{1}{2}\left(\log \frac{H_{i t}}{L_{i t}}\right)^{2}-(2 \log 2-1)\left(\log \frac{C_{i t}}{O_{i t}}\right)^{2}} .
$$

Figures 1 and 2 display the three inverse ETFs' turnover and volatility moves over the sample period, respectively. Table 1 presents summary statistics that describe the trading activity of the three inverse ETFs. We can observe that the trades of the two inverse ETFs that inversely track China's stock indices are more active and volatile. While Fubon SSE 180 Inversed Index ETF (00634R) has the highest share turnover among the three inverse ETFs, Yuanta Daily CSI 300 Bear -1X ETF (00638R) excels the other two inverse ETFs in price volatilities.

Table 1. Summary statistics for the trading-activity variables of the three inverse ETFs

\begin{tabular}{|l|c|c|c|c|}
\hline & $\begin{array}{c}\text { Share turnover } \\
\text { (thousand shares) }\end{array}$ & $\begin{array}{c}\text { Turnover rate } \\
(\%)\end{array}$ & $\begin{array}{c}\text { HL_volt } \\
(\%)\end{array}$ & $\begin{array}{c}\text { OHLC_volt } \\
(\%)\end{array}$ \\
\hline Panel A: 00632R (289 observations) & \multicolumn{3}{|l|}{} \\
\hline Mean & 14682.06 & 4.81 & 1.04 & 0.63 \\
\hline
\end{tabular}

\footnotetext{
${ }^{1}$ An index compiled by China Securities Index (CSI) Co., Ltd covers about 70\% of the market capitalization of the Shanghai and Shenzhen markets.
} 
Table 1 (cont.). Summary statistics for the trading-activity variables of the three inverse ETFs

\begin{tabular}{|c|c|c|c|c|}
\hline & $\begin{array}{l}\text { Share turnover } \\
\text { (thousand shares) }\end{array}$ & $\begin{array}{c}\text { Turnover rate } \\
(\%)\end{array}$ & $\begin{array}{c}H L_{-} \text {volt } \\
(\%)\end{array}$ & $\underset{(\%)}{O H L C \text { volt }}$ \\
\hline \multicolumn{5}{|c|}{ Panel A: 00632R (289 observations) } \\
\hline Median & 10159.00 & 3.45 & 0.92 & 0.56 \\
\hline Maximum & 62199.00 & 26.25 & 6.63 & 4.54 \\
\hline Minimum & 1694.00 & 0.69 & 0.26 & 0.13 \\
\hline Std. dev. & 12713.92 & 4.17 & 0.69 & 0.39 \\
\hline Skewness & 1.4815 & 2.1175 & 4.0767 & 4.3528 \\
\hline Kurtosis & 4.7341 & 8.6266 & 30.5118 & 39.1772 \\
\hline \multicolumn{5}{|c|}{ Panel B: 00634R (272 observations) } \\
\hline Mean & 20158.77 & 9.68 & 2.52 & 1.51 \\
\hline Median & 15122.00 & 7.94 & 2.13 & 1.29 \\
\hline Maximum & 130329.00 & 56.68 & 12.18 & 8.18 \\
\hline Minimum & 1840.00 & 1.05 & 0.61 & 0.39 \\
\hline Std. dev. & 15441.86 & 7.32 & 1.57 & 0.95 \\
\hline Skewness & 2.4570 & 2.9962 & 2.4232 & 2.7338 \\
\hline Kurtosis & 13.2838 & 15.6128 & 11.8573 & 14.4666 \\
\hline \multicolumn{5}{|c|}{ Panel C: 00638R (159 observations) } \\
\hline Mean & 8029.31 & 15.54 & 3.20 & 3.16 \\
\hline Median & 5402.00 & 8.49 & 1.95 & 1.20 \\
\hline Maximum & 39867.00 & 114.22 & 99.95 & 256.60 \\
\hline Minimum & 570.00 & 1.24 & 0.45 & 0.30 \\
\hline Std. dev. & 7566.63 & 19.65 & 7.96 & 20.26 \\
\hline Skewness & 1.9013 & 3.0122 & 11.4317 & 12.4227 \\
\hline Kurtosis & 6.7030 & 12.8641 & 139.1228 & 155.8786 \\
\hline
\end{tabular}

\section{Empirical results}

Through coefficient tests, share turnovers are proved redundant, and turnover rates, compared to share turnovers, are found to have significant explanatory power for future index returns. Similarly, OHLC_volt, that considers more information than $H L_{-}$volt, is found to explain future index returns better. Therefore, turnover rates and $O H L C \_$volt are used as turnover and volatility variables, respectively, in the estimation of equation (1). Except the occasion of one-day future index returns $\left(X \_r e t_{i,}(t+1)\right.$ o, $\left.(t+1) c\right)$, all panel estimations incorporate cross-sectional fixed effects, because fixed effects testing proves that these fixed effects are not redundant. Moreover, in light of the frequent heteroskedasticity and serial correlation present in the errors of financial time-series data, the White period method is applied to obtain robust standard errors and subsequent $p$-values for coefficient inferences. Table 2 reports the estimation results.

Table 2. Inverse ETF trading and future index returns

$X_{-} \operatorname{ret}_{i,(t+1) o,(t+j) c}=\alpha+\beta_{1}$ turn $_{i, t}+\beta_{2}$ Pvolt $_{i, t}+\beta_{3} X_{-} \operatorname{ret}_{i(t-j+1) o, t c}+\varepsilon_{i, t}$.

\begin{tabular}{|c|c|c|c|c|c|}
\hline Dependent variable & $\begin{array}{l}\text { Intercept } \\
\qquad(\alpha)\end{array}$ & $\begin{array}{c}\text { Turnover rate } \\
\left(\beta_{1}\right)\end{array}$ & $\begin{array}{c}\text { OHLC_volt } \\
\left(\beta_{2}\right)\end{array}$ & $\begin{array}{l}\text { Lagged index return } \\
\left(\beta_{3}\right)\end{array}$ & Adjusted $R^{2}$ \\
\hline$X \_r e t_{i,(t+1) o,(t+1) c}$ & $\begin{array}{c}-0.1379 \\
(0.0520)^{*}\end{array}$ & $\begin{array}{c}0.0232 \\
(0.0000)^{*+*}\end{array}$ & $\begin{array}{c}-0.0007 \\
(0.0202)^{*+}\end{array}$ & $\begin{array}{c}0.0249 \\
(0.0273)^{* *}\end{array}$ & 0.0179 \\
\hline$X \_$ret $t_{i,(t+1) o,(t+2) c}$ & $\begin{array}{c}-0.3688 \\
(0.0000)^{*+*}\end{array}$ & $\begin{array}{c}0.0429 \\
(0.0000)^{* * *}\end{array}$ & $\begin{array}{c}0.0033 \\
(0.0225)^{* *}\end{array}$ & $\begin{array}{c}-0.1353 \\
(0.0000)^{+* *}\end{array}$ & 0.0418 \\
\hline$X \_$reti, $(t+1),(t+3) c$ & $\begin{array}{c}-0.4202 \\
(0.0000)^{*+*+}\end{array}$ & $\begin{array}{c}0.0463 \\
(0.0000)^{* *+}\end{array}$ & $\begin{array}{c}0.0115 \\
(0.0002)^{*+*+*}\end{array}$ & $\begin{array}{l}-0.0091 \\
(0.4463)\end{array}$ & 0.0205 \\
\hline$X \_$reti, $(t+1),(t+4) c$ & $\begin{array}{c}-0.5220 \\
(0.0000)^{*+*}\end{array}$ & $\begin{array}{c}0.0549 \\
(0.0000)^{* * *}\end{array}$ & $\begin{array}{c}0.0182 \\
(0.0000)^{*+*}\end{array}$ & $\begin{array}{l}-0.0206 \\
(0.4195)\end{array}$ & 0.0266 \\
\hline$X \_r e t t_{i}(t+1),(t+5) c$ & $\begin{array}{c}-0.7051 \\
(0.0001)^{*+*}\end{array}$ & $\begin{array}{c}0.0785 \\
(0.0001)^{* * *}\end{array}$ & $\begin{array}{c}0.0110 \\
(0.0340)^{* *}\end{array}$ & $\begin{array}{c}-0.0507 \\
(0.0462)^{* *}\end{array}$ & 0.0395 \\
\hline
\end{tabular}

Note: Those in parentheses are $p$-values for the intercept and the coefficient estimates. $*, * *$ and $* * *$ indicates significance at the $10 \%, 5 \%$ and $1 \%$ levels, respectively.

The results show that the inverse ETF turnover is significantly and positively related to all-period future index returns, indicating that what the ETF turnover rates convey is not a bearish, but more like a bullish signal to the market. Inverse ETF's trading, thus, is similar to a panic index. When inverse ETF turnover climbs to a high point, it means that the index low is not far away and the index is about to 
reverse upward; on the contrary, when inverse ETF turnover drops to a low point, it means the index high is very close and the index is going to reverse downward. This positive relationship between inverse ETF turnover and future index returns answers to the fact that the proportion of retail trading in the whole ETF turnover values has risen to over $50 \%$ since the fourth quarter of 2014, indicating that, in this market, inverse ETF trades may not reflect an informed pessimistic trading but a lagging or less-informed bearish signal.

The results also show that the current inverse ETF price volatility is significantly and positively related to two- to five-day future index returns, indicating that the more severe the inverse ETF prices fluctuate, the greater the future index returns get. Such indication demonstrates once again the above argument, which claims that, in this market, inverse ETF trades may not reflect an informed pessimistic trading, but a lagging or less-informed bearish signal. Therefore, three important inferences drawn from all above results are: (1) the trading of inverse ETFs (turnover rate and price volatility) cannot predict future negative index returns; (2) the trading of inverse ETFs may not stand for informed pessimistic trading, so it cannot convey a bearish signal to the rest of the market; (3) the trading activities in inverse ETFs do provide information about future index returns, yet what they reflect may be a lagging or lessinformed bearish signal. Such implication answers to the fact that the proportion of retail traders, whom are generally considered less-informed traders, in the whole ETF turnover values has risen to over $50 \%$ since the fourth quarter of 2014.

\section{Conclusion}

This study examines the trading activity of inverse ETFs to determine if the trading of inverse ETFs reflects informed pessimistic trading and can convey a bearish signal to the market as a result. The advantage this analysis brings about is twofold: understanding the information content of inverse ETF trading and finding out the information status of inverse ETF traders.

The results show that the inverse ETF turnover is significantly and positively related to all-period future index returns, indicating that what the inverse ETF turnover rates convey is not a bearish, but more a bullish signal to the market. Inverse ETF's trading is similar to a panic index. The results also show that the current inverse ETF price volatility is significantly and positively related to two- to fiveday future index returns, indicating that the more severe the inverse ETF prices fluctuate, the greater the future index returns may get, and demonstrating again inverse ETF trades in this market may not reflect an informed pessimistic trading but a lagging or less-informed bearish signal. Therefore, this paper concludes that the trading of inverse ETFs cannot predict future negative index returns. The trading of inverse ETFs may not reflect informed pessimistic trading and cannot convey a bearish signal to the rest of the market. The trading activities in inverse ETFs do provide information about future index returns, yet what they reflect may be a lagging or less-informed bearish signal. Such implication responds to the fact that the proportion of retail traders, whom are generally considered less-informed traders, in the whole ETF turnover values has risen to over $50 \%$ since the fourth quarter of 2014.

\section{References}

1. Ackert, L.F. and Athanassakos, G. (2005). The relationship between short interest and stock returns in the Canadian market, Journal of Banking and Finance, 29(7), pp. 1729-1749.

2. Aitken, M.J., Frino, A., McCorry, M.S. and Swan, P.L. (1998). Short sales are almost instantaneously bad news: evidence from the Australian Stock Exchange, Journal of Finance, 53, pp. 2205-2223.

3. Angel, J.J., Christophe, S.E. and Ferri, M.G. (2003). A close look at short selling on Nasdaq, Financial Analysts Journal, 59(6), pp. 66-74.

4. Asquith, P., Pathak, P.A. and Ritter, J.R. (2005). Short interest, institutional ownership, and stock returns, Journal of Financial Economics, 78(2), pp. 243-276.

5. Blau, B.M. and Brough, T.J. (2011). Is the trading of inverse ETFs a bearish signal? Journal of Trading, 6(3), pp. 32-40.

6. Boehme, R.D., Danielsen, B.R. and Sorescu, S.M. (2006). Short-sale constraints, differences of opinion, and overvaluation, Journal of Financial and Quantitative Analysis, 41(2), p. 455.

7. Boehmer, E., Huszar, Z.R. and Jordan, B.D. (2010). The good news in short interest, Journal of Financial Economics, 96(1), pp. 80-97.

8. Brent, A., Morse, D. and Stice, E.K. (1990). Short interest: explanations and tests, Journal of Financial and Quantitative Analysis, 25(2), pp. 273-289.

9. Bris, A., Goetzmann, W. and Zhu, N. (2007). Efficiency and the bear: short sales and markets around the world, Journal of Finance, 62, pp. 1029-1079.

10. Chang, E.C., Cheng, J.W. and Tu, Y. (2007). Short-sales constraints and price discovery: evidence from the Hong Kong market, Journal of Finance, 62, pp. 2097-2121. 
11. Dechow, P.M., Hutton, A.P., Meulbroek, L. and Sloan, R.G. (2001). Short-sellers, fundamental analysis, and stock returns, Journal of Financial Economics, 61, pp. 77-106.

12. Desai, H., Ramesh, K., Thiagarajan, S.R. and Balachandran, B.V. (2002). An investigation of the informational role of short interest in the Nasdaq market, Journal of Finance, 57, pp. 2263-2287.

13. Diamond, D.W. and Verrecchia, R.E. (1987). Constraints on short-selling and asset price adjustment to private information, Journal of Financial Economics, 18, pp. 277-311.

14. Diether, K., Lee, K. and Werner, I. (2009). Short-sale strategies and return predictability, Review of Financial Studies, 22, pp. 575-607.

15. Farinella, J.A., Graham, J.E. and McDonald, C.G. (2001). Does High Short Interest Lead Underperformance? The Journal of Investing, 10(2), pp. 45-52.

16. Figlewski, S. (1981). The informational effects of restrictions on short sales: some empirical evidence, Journal of Financial and Quantitative Analysis, 16(4), pp. 463-476.

17. Figlewski, S. and Webb, G.P. (1993). Options, short sales, and market completeness, The Journal of Finance, 48(2), pp. 761-777.

18. Garman, T. and Klass, M. (1980). On the estimation of security price volatilities from historical data, Journal of Business, 53, pp. 67-78.

19. Jones, C.M. and Lamont, O.A. (2002). Short-sale constraints and stock returns, Journal of Financial Economics, 66(2), pp. 207-239.

20. Miller, E.M. (1977). Risk, Uncertainty and Divergence of Opinion, Journal of Finance, 32, pp. 1151-1168.

21. Senchack, A.J. and Starks, L.T. (1993). Short-sale restrictions and market reaction to short-interest announcements, Journal of Financial and Quantitative Analysis, 28(2), pp. 177-194.

22. Sum, V. and Lin, J.C. (2015). Short interest ratio and equity market return: causality and impulse response functions, Advances in Financial Planning and Forecasting, 6, pp. 233-247.

23. Woolridge, J.R. and Dickinson, A. (1994). Short selling and common stock prices, Financial Analysts Journal, 50(1), pp. 20-28.

24. Zhou, K. and Wong, M.C. (2011). Impact of Short Selling on China Stock Prices, Handbook of Short Selling.

Appendix

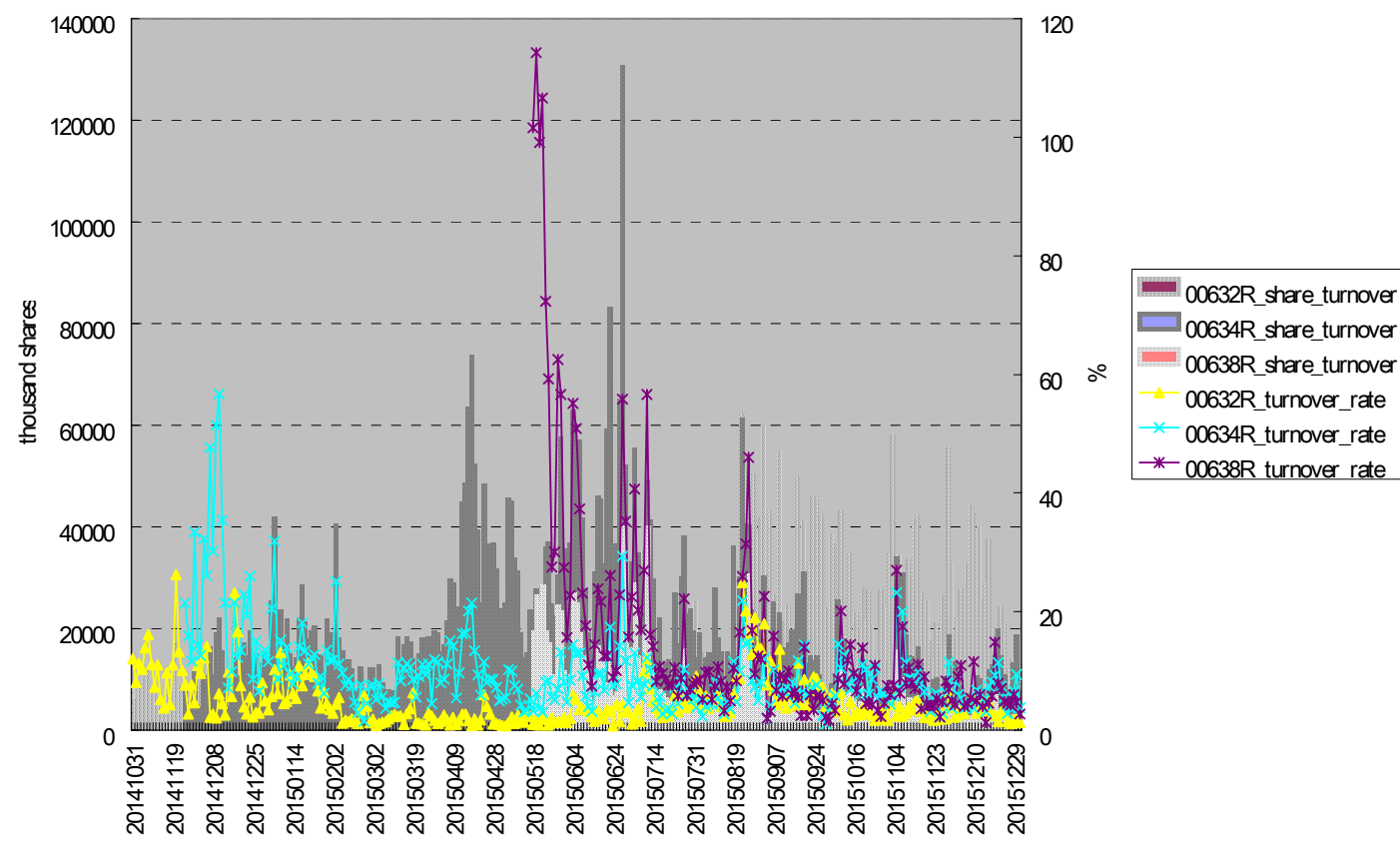

Fig. 1. Daily turnover of the three inverse ETFs, October 31, 2014 to December 31, 2015 
Investment Management and Financial Innovations, Volume 13, Issue 2, 2016

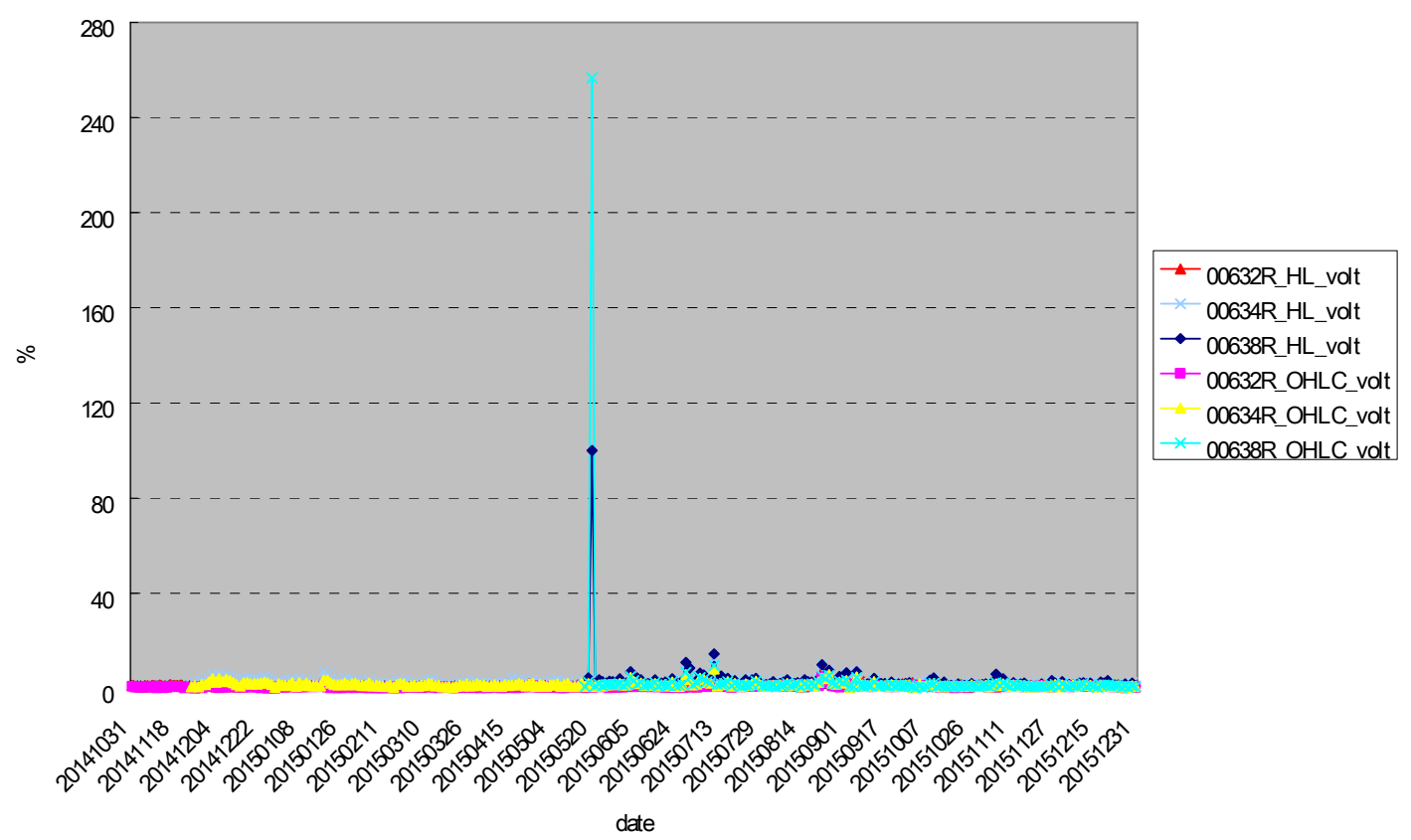

Fig. 2. Daily volatility of the three inverse ETFs, October 31, 2014 to December 31, 2015 